\title{
The PLATINO Study: Contributions to COPD Knowledge
}

\author{
Maria Montes de Oca, MD, PhD' and Maria Victorina Lopez-Varela, MD²
}

${ }^{1}$ Department of Pneumonology, Hospital Universitario de Caracas, Facultad de Medicina, Universidad Central de Venezuela, Caracas, Venezuela; ${ }^{2}$ Faculty of Medicine, Universidad de la República, Hospital Maciel, Montevideo, Uruguay

\section{ABSTRACT}

The PLATINO study was a large survey in Latin America, originally aimed to describe the epidemiology of chronic obstructive pulmonary disease (COPD). A baseline, crosssectional, population-based survey was conducted in five major cities: São Paulo (Brazil), Santiago (Chile), Mexico City (Mexico), Montevideo (Uruguay), and Caracas (Venezuela). A follow-up study was completed five to nine years later in three of five original centres. This review provides information from the Spanish acronym: Latin American Project for Research in Pulmonary Obstruction (PLATINO Study) on COPD epidemiology in the region (prevalence, accurate/inaccurate diagnosis, and treatment). Available data on disease risk factors, clinical patterns, follow-up prevalence, and diagnosis stability over time, as well as mortality, are also presented. (BRN Rev. 2017;3:3-17)

Corresponding author: montesdeoca.maria@gmail.com

Co-author e-mail: MVLV: victorina.lopezvarela@gmail.com

Key words: Asthma-COPD Overlap Syndrome (ACOS). COPD. Epidemiology. PLATINO study. 


\section{BACKGROUND}

Chronic obstructive pulmonary disease (COPD) is a major global problem with high prevalence, morbidity, and mortality. In Latin America the situation is complex due to the fast epidemiologic and demographic transition, with increases in chronic diseases as a result of the aging population.

Few studies have assessed COPD epidemiology in Latin America ${ }^{1-3}$. The PLATINO study (Spanish acronym: Latin American Project for Research in Pulmonary Obstruction) was the first large survey in Latin America to assess the COPD burden in five low- and middleincome countries: São Paulo (Brazil), Santiago (Chile), Mexico City (Mexico), Montevideo (Uruguay), and Caracas (Venezuela) 2,3. These sites represent different geographical areas of
Latin America and the largest metropolitan area in each participating country. The Proyecto Latinoamericano de Investigación en $\mathrm{Ob}$ strucción Pulmonar (PLATINO Study) baseline study was conducted from 2002 to 2004 as an initiative of the Asociación Latinoamericana del Tórax (ALAT) (Fig. 1). Data from this study have filled an important knowledge gap in the COPD epidemiology in Latin America and have allowed analysing different characteristics of the disease in an unbiased population.

The cross-sectional nature of the PLATINO baseline study (a visit at one point in time) did not provide temporal data and thus does not allow analysing some important COPD outcomes. Therefore, after five years, a follow-up study was conducted in three of the original five PLATINO sites (Fig. 2).

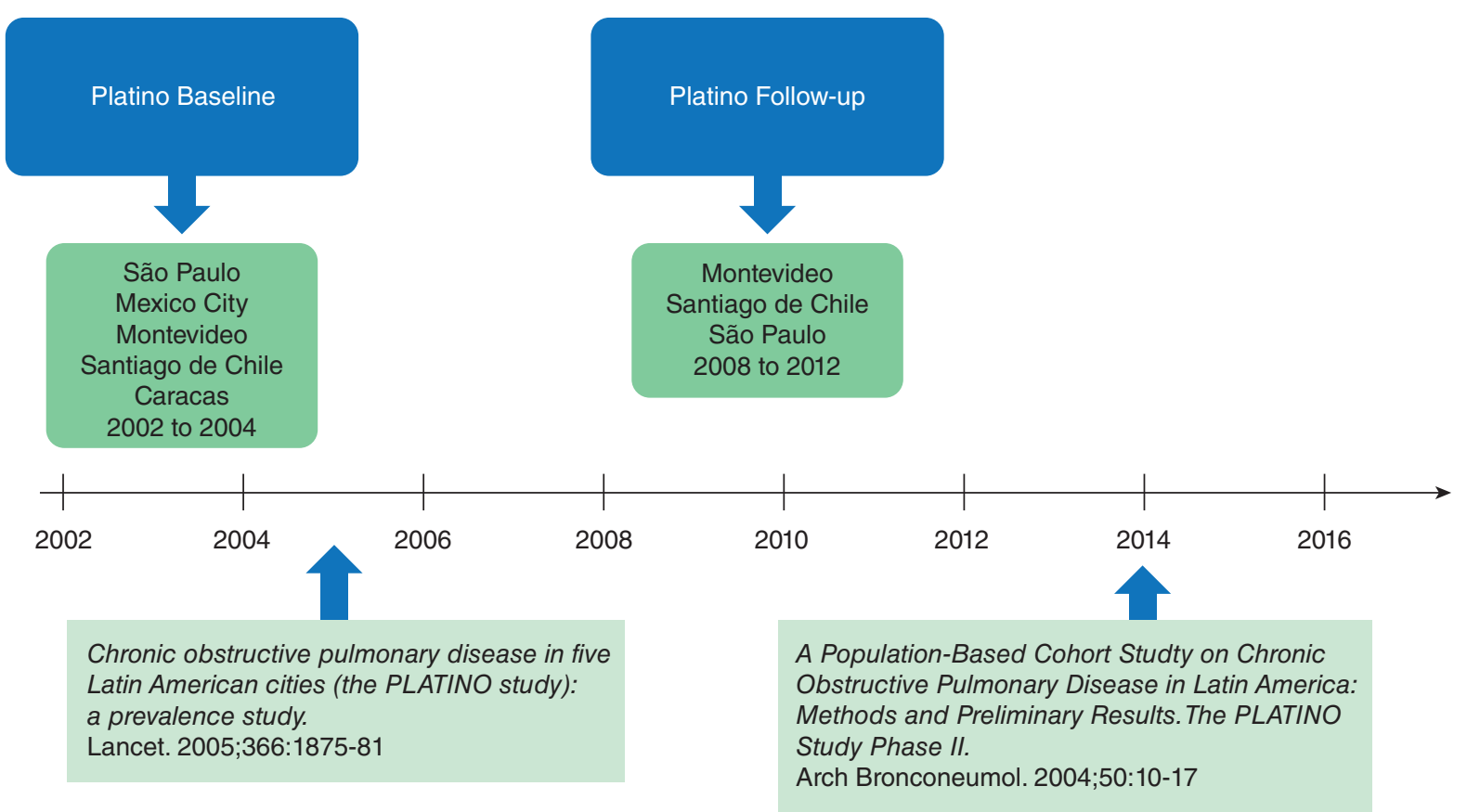

Figure 1. The PLATINO study chronology. 
Figure 2. COPD prevalence in the PLATINO baseline population by different spirometric criteria before and after the use of bronchodilator.

$\mathrm{BD}$ : bronchodilator; $\mathrm{FEV}_{1}$ : forced expiratory volume in 1 second; $\mathrm{FEV}_{6}$ : forced expiratory volume in 6 seconds; FVC: forced vital capacity; LLN: lower limit of normal.

This review provides information from the PLATINO study on COPD epidemiology in the region (prevalence, accurate/inaccurate diagnosis, and treatment of disease). It also provides information on risk factors, clinical characteristics of patients with spirometric COPD diagnosis, prevalence in the follow-up study, diagnosis stability over time, and mortality.

\section{DESIGN AND GENERAL CHARACTERISTICS OF THE PLATINO BASELINE STUDY}

The PLATINO baseline study included all adults $\geq 40$ years old living in the selected households ${ }^{2,3}$. Information was collected on several factors potentially associated with COPD (demographics, smoking habits, years of education, respiratory symptoms, exacerbation, comorbidities, respiratory medication use, and prior spirometry) ${ }^{2,3}$. Subjects performed spirometry pre- and post-bronchodilator (post-BD). A total of 1,000 subjects were interviewed in Sao Paulo, 1,063 in Mexico City, 943 in Montevideo, 1,208 in Santiago, and 1,357 in Caracas and spirometry was undertaken in 99\% $\%^{2,3}$. The overall response rate (including spirometry) was $83.7 \%$ in São Paulo, $79.5 \%$ in Santiago, 68.9\% in Mexico City, 80\% in Montevideo, and 71.7\% in Caracas ${ }^{2,3}$.

\section{CONTRIBUTION TO THE EPIDEMIOLOGY AND COPD BURDEN IN LATIN AMERICA}

\section{Prevalence and risk factors}

COPD is a leading cause of global morbidity and mortality, associated with a high economic and social burden ${ }^{4,5}$. There are many studies of COPD prevalence and their results document wide variations across countries and regions and between different groups within countries ${ }^{1,3,6}$.

Overall COPD prevalence in the PLATINO study by the post-BD forced expiratory volume in 1 second/forced vital capacity $\left(\mathrm{FEV}_{1} /\right.$ FVC) $<0.70$ criteria was $14.3 \%$ (ranging from $7.8 \%$ in Mexico City to $19.7 \%$ in Montevideo $)^{3}$. Global prevalence by the lower limit of normal (LLN) criteria of post-BD $\mathrm{FEV}_{1} / \mathrm{FVC}$ ratio was $11.7 \%$ and even lower when using the post-BD $\mathrm{FEV}_{1} / \mathrm{VEF}_{6}<\mathrm{LLN}$ criteria $(9.5 \%)^{7}$. A survey in five Colombian cities found a COPD prevalence ranging from 6.2 to $13.5 \% 1$. These findings suggest that the burden of COPD in Latin America is high, and that prevention of the disease is a public health priority in the region. 
In all PLATINO cities, there was a consistent pattern of higher prevalence in men, older people, those with less education and lower body-mass index (BMI), and greater tobacco exposure $^{3}$. The prevalence of COPD in all sites was significantly higher in men than in women (combined prevalence in males 18.9\%, and $11.3 \%$ in females $)^{3}$. The Burden of $\mathrm{Ob}-$ structive Lung Diseases (BOLD), a study with similar methodology to PLATINO, subsequently reported a COPD prevalence of GOLD stage $\geq 2$ of $10.1 \%$ overall, $11.8 \%$ for men, and $8.5 \%$ for women ${ }^{8}$. These results, in accordance with the PLATINO findings, support the higher prevalence of disease in men worldwide.

In PLATINO the risk factors with the highest etiological fractions for COPD were age, current smoking, indoor coal exposure, and dust exposure in the workplace ${ }^{3}$. Attributable risk for COPD was $52 \%$ for $\geq 60$ years of age, and for modifiable factors the risk was $27 \%$ for current smokers, $11 \%$ for coal exposure $\geq 10$ years, and 9\% for dust exposure in workplace $\geq 10$ years $^{3}$. Other factors, including male sex, poor education, biomass exposure, history of tuberculosis, low BMI, and childhood admission due to respiratory problems, presented an attributable risk $<10 \%{ }^{3}$.

The BOLD study also assessed the associations between spirometric-defined COPD and main risk factors. Similar to PLATINO, they found significant associations between COPD and smoking, environmental tobacco exposure, age, education, tuberculosis, hospitalization for respiratory illness before the age of 10 years, a family history of COPD, and number of years worked in dusty jobs 9 .

\section{COPD diagnosis problems in epidemiologic studies}

COPD surveys have identified important differences in the distribution of the disease prevalence and underdiagnosis. In PLATINO, COPD underdiagnosis (individuals without a prior diagnostic label consistent with COPD with airflow limitation) was $89 \%$ and misdiagnosis $64 \%$ (individuals with prior COPD medical diagnosis without airflow limitation) ${ }^{10}$. Only $20 \%$ of the surveyed individuals had performed a spirometry at some time in their lives. Underdiagnosis was associated with younger age, lower severity of airway obstruction, fewer respiratory symptoms (cough, phlegm, wheezing, shortness of breath), and no prior diagnosis of asthma ${ }^{10}$.

Lamprecht et al. ${ }^{11}$ reported an overall COPD underdiagnosis prevalence of $81.4 \%$ in national and international population surveys [BOLD, PLATINO, Epidemiologic Study of COPD in Spain (EPI-SCAN) and Prevalence of COPD in Prevalence of Chronic Obstructive Pulmonary Disease in five Colombian cities (PREPOCOL)]. Underdiagnosis was associated with male sex, younger age, never and current smoking, lower education, no previous spirometry, and milder airflow limitation ${ }^{11}$.

These results confirm COPD underdiagnosis as a major health problem and highlight the need to improve diagnoses worldwide.

\section{COPD undertreatment and overtreatment}

Despite the availability of national and international COPD guidelines, evidence from real-life studies suggests that inadequate COPD treatment is common ${ }^{12,13}$. 
PLATINO showed that less than $25 \%$ of patients with spirometric COPD criteria had received any respiratory medication in the previous year ${ }^{14}$. Among those with previous correct COPD diagnosis, three-quarters (75.6\%) were receiving any respiratory medication (43\% inhaled medication and 36\% bronchodilators $)^{14}$. In addition, the majority of patients used the medication based on symptoms rather than on a regular basis, independently of disease severity ${ }^{14}$.

Another PLATINO subanalysis, focused on the use of bronchodilators inhaled or corticosteroids in persons with little evidence of chronic respiratory disease, indicated that these medications are frequently used in individuals $\geq 40$ years old without a previous diagnosis of asthma, COPD, or the presence of airway obstruction ${ }^{15}$. Over $50 \%$ of subjects using medication for airflow limitation were not obstructed. Therefore, respiratory medication also appears to be used in subjects incorrectly diagnosed as COPD ${ }^{15}$.

In light of these evidences, investments should also be made in terms of improving COPD treatment and encouraging appropriate therapies among primary care physicians to limit the risks and costs associated with undertreatment and overtreatment and improve patient outcomes.

\section{CONTRIBUTION \\ TO THE CHARACTERISTICS \\ OF THE DISEASE AND POTENTIAL COPD PHENOTYPES}

The PLATINO baseline study offers an opportunity for analysing characteristics of the disease and potential patient subgroups in a large population-based sample.

\section{Regional spirometric reference values and acute bronchodilator responsiveness in COPD}

Since PLATINO participants were included by population-sampling methods, spirometric reference values before and after bronchodilators were generated from individuals without a history of respiratory disease. Proposed values represent a step forward for better spirometry in Latin America ${ }^{16,17}$.

Acute bronchodilator responsiveness (BDR) is an area of discussion in COPD. In a selected COPD population, Calverley et al. ${ }^{18}$ reported more than three-quarters of patients had an improvement in expiratory airflow over the generally accepted minimum clinically important difference $(100 \mathrm{ml})$. Data from the Understanding the Potential Long-Term Impacts on Function with Tiotropium (UPLIFT) cohort indicated that $53.9 \%$ of patients demonstrated $12 \%$ and $200 \mathrm{ml} \mathrm{FEV}_{1}$ improvement after the administration of two bronchodilators $^{19}$. In the Lung Health Study, approximately $20 \%$ of COPD patients demonstrated initial $\mathrm{FEV}_{1}$ response $\geq 200 \mathrm{ml}^{20}$.

Along this line, a sub-analysis of PLATINO assessed the acute BDR in subjects with and without airway obstruction. Over two-thirds of COPD subjects had no acute $\mathrm{BDR}^{21}$. Depending on the criterion used, the proportion of subjects with acute BDR ranged between $15.0-28.2 \%$ in the COPD group, $11.4-21.6 \%$ in reversible obstructed individuals, and 2.7$7.2 \%$ in healthy respiratory subjects ${ }^{21}$. In the 
COPD group, 28\% met the ATS criteria for acute BDR. An FVC acute BDR was more common than $\mathrm{FEV}_{1}$ response; $24 \%$ had isolated $\mathrm{FEV}_{1}$ reversibility, 38\% isolated FVC reversibility, and $38 \%$ both $^{21}$. There was a substantial overlap in $\mathrm{FEV}_{1}$ and FVC changes after bronchodilator use in individuals with COPD and those with reversible obstruction, which makes it difficult to determine a threshold for separating these groups ${ }^{21}$.

Subsequently, BOLD provided reference values for BDR worldwide that confirm guideline estimates for a clinically significant level of BDR in bronchodilator testing 22 . They found that the BDR threshold for people with chronic airflow limitation was lower when asthma was excluded, with considerable overlap between the groups. They also found that the proportion with reversibility measured by changes in $\mathrm{FEV}_{1}$ generally decreased as COPD severity increased, while that measured by changes in FVC increased with increasing COPD severity.

The PLATINO findings are consistent with other epidemiologic studies ${ }^{20,22}$, suggesting that acute BDR in COPD is minor and less than considered as significant. Greater bronchodilator increase in FVC compared to $\mathrm{FEV}_{1}$ support the use of lung volume-based measures (volume response) of reversibility in addition to $\mathrm{FEV}_{1}$-based measures (flow response). Finally, all the studies consistently indicate that BDR has limited diagnostic value in differentiating asthma from COPD.

\section{COPD screening}

Limited spirometry availability is an important barrier for confirming COPD diagnosis.
Normal pre-BD peak expiratory flow (PEF) in adults may rule out clinically significant COPD. Combined data from two populationbased studies (PLATINO and BOLD) was used to assess whether PEF (pre-BD) identified spirometric-confirmed post-BD airflow obstruction $^{23}$. A PEF screening cut-off point of $70 \%$ predicted effectively ruled out COPD patients in GOLD grades 3-4 (NPV: 99.9\%) ${ }^{23}$. Additionally, using this cut-off point as a screening tool to rule out severe airflow limitation, only $12 \%$ of subjects with COPD risk factors would require confirmatory spirome$\operatorname{try}^{23}$. The addition of PEF measurement to a simple screening questionnaire may rule out patients with severe-to-very severe COPD without the need of confirmatory pre- and post-BD spirometry testing ${ }^{23}$.

Subsequently, BOLD compared the screening efficiency of differently staged algorithms that used questionnaire data and/or PEF to identify persons at risk for COPD and, hence, needing confirmatory spirometry ${ }^{24}$. For moderate-to-severe COPD, the use of questionnaire data alone permitted high sensitivity (97\%), but required confirmatory spirometry in $80 \%$ of participants. Using PEF confirmatory spirometry was needed in only $19-22 \%$ of subjects, with $83-84 \%$ sensitivity ${ }^{24}$. For severe COPD, PEF achieved 91-93\% sensitivity, requiring confirmatory spirometry in $9 \%$. Cost analysis suggested that staged screening algorithm using only PEF initially, followed by confirmatory spirometry as needed, was the most cost-effective case-finding strategy.

The results support the use of PEF as a simple, cost-effective, initial screening tool for conducting COPD case-finding in adults aged $\geq 40$ years. 


\section{COPD and comorbidities}

Comorbidities are frequent in COPD and contribute to disease expression, disease burden, and survival ${ }^{25-28}$. In a large cohort of COPD patients undergoing pulmonary rehabilitation, the authors reported at least one chronic comorbidity in $51 \%$ of patients ${ }^{29}$. Comorbidities, defined as other chronic medical conditions, including coronary artery disease, diabetes mellitus, osteoporosis, and muscle weakness, are common in COPD, but their prevalence varies between studies ${ }^{30}$.

In PLATINO, the number of comorbidities was significantly higher in subjects with COPD compared with non-COPD subjects, regardless of their smoking status ${ }^{31}$. Reported comorbidities in decreasing frequency were: any cardiovascular disease, hypertension, peptic ulcer, heart disease, diabetes, cerebrovascular disease, asthma, and lung cancer $^{31}$. Age, female sex, and higher BMI were the main factors associated with comorbidities $^{31}$. The number of self-reported comorbidities was associated with a deterioration in general health status independently of the COPD status ${ }^{31}$.

These findings indicate that comorbidities are frequent in COPD. Therefore, an active search and approach for the most important comorbidities is recommended, and essential to improve disease management.

\section{Sex and COPD expression}

The perception that COPD is a disease of older male smokers is obsolete; COPD affects both men and women worldwide ${ }^{32}$.
Although sex-specific COPD data are limited, some evidences from selected COPD populations support sex differences in the clinical expression of the disease. In general, women with COPD compared to men seem to be younger, smoke less, have lower BMI and socioeconomic status, report more anxiety and depression, have lower exercise capacity, and worse symptoms and health-related quality of life $\mathrm{e}^{33-38}$. However, at similar severity by BODE index and $\mathrm{FEV}_{1}$, women have significantly better survival than men ${ }^{39}$.

In the entire PLATINO population, females reported more dyspnoea and physical limitations and worse general health status than males ${ }^{40}$. A higher proportion of females with COPD compared with males reported their general health status as fair-to-poor (41 versus $34 \%)^{40}$. The distribution of COPD severity was similar between genders, but actively smoking females had more severe obstruction than males, despite similar smoking exposure $^{40}$.

These findings indicate that manifestations of COPD may differ in females; therefore, a multi-disciplinary approach for COPD in women is required, including increased awareness, risk minimization, and a greater clarity of specific factors affecting the risk, disease progression, and treatment.

\section{Body mass index and COPD}

The BMI is identified as an independent prognostic factor for COPD, with a clear association between decreased BMI and increased mortality ${ }^{41,42}$. 
A progressive increment in the proportion of COPD subjects was observed as BMI decreased in the PLATINO population ${ }^{43}$. Compared with non-COPD subjects, the proportion of COPD subjects with BMI $<25 \mathrm{~kg} / \mathrm{m}^{2}$ (underweight and normal-weight categories) was higher, and lower in the obese category ${ }^{43}$. In men with COPD, aging, current smoking, and severe airway obstruction were the main factors associated with lower BMI, whereas in women these were current smoking, lower education, and severe airway obstruction ${ }^{43}$.

These results are in line with a recent BOLD analysis, which showed, after adjustment for confounders, that in subjects with chronic airflow limitation, low BMI was more frequent (OR: 2.23; 95\% CI: 1.75-2.85), and conversely, obesity was less frequent (OR: 0.78; 95\% CI: 0.65-0.94). All these results clearly indicate an association between lower BMI and $\mathrm{COPD}^{44}$.

\section{Exacerbation frequency}

COPD exacerbations are important events associated with an accelerated decline in lung function, poor quality of life, and increased mortality ${ }^{45-49}$. They are the most common conditions requiring hospital admission, contributing substantially to the economic burden of disease $e^{50-53}$.

In the Evaluation of COPD Longitudinally to Identify Predictive Surrogate Endpoints (ECLIPSE) study, approximately $20 \%$ of patients with GOLD stage 2 and $47 \%$ of those with stage 4 were classified as "frequent exacerbators" (defined as two or more exacerbations annually) ${ }^{54}$.
Less than one-third of the PLATINO baseline population reported ever having had an exacerbation, $7.9 \%$ reported having an exacerbation in the past-year, with $6.2 \%$ requiring a doctor visit and $2 \%$ requiring hospitalization $^{55}$. The proportion of individuals with an exacerbation increased as airway obstruction worsened $(4.2 \%$ in GOLD stage 1 versus $28.9 \%$ in grades $3-4)^{55}$. The other factors associated with having an exacerbation were dyspnoea and prior diagnosis of asthma $^{55}$. The highest proportion (> 55\%) of COPD patients categorized as mild-to-moderate explains the lower frequency of individuals with an exacerbation compared to selected COPD populations. However, they consistently indicate that exacerbations become more frequent as the severity of COPD increases.

\section{Chronic bronchitis phenotype}

The presence of chronic bronchitis (CB) in COPD patients has been associated with worse quality of life and symptoms, and increased disease severity and risk of exacerbation ${ }^{56-58}$. The reported prevalence of $\mathrm{CB}$ ranges from 14 to $74 \%$ of all COPD patients, probably due to varying definitions, different study populations, and study designs ${ }^{56,58,59}$.

In PLATINO, the proportion of COPD subjects with $\mathrm{CB}$ defined as the presence of phlegm most days, $\geq 3$ months/years for $\geq 2$ years, was $14.4 \%$ and was associated with increased disease severity (lower pulmonary function, more respiratory symptoms and exacerbations), worse health status, and more physical activity limitation ${ }^{60}$. These findings are in line with 
those reported in selected COPD patients and support the fact that $\mathrm{CB}$ is associated with worse COPD outcomes.

\section{Asthma-COPD overlap syndrome}

Both COPD and asthma are common chronic airway diseases in adults, and therefore, the coexistence in some individuals is likely and has been recognized as asthma-COPD overlap syndrome (ACOS).

Proposed definitions for ACOS vary widely and include patients with: (i) COPD and previous asthma diagnosis; (ii) spirometric COPD definition and significant reversibility; and (iii) asthma and persistent airflow limitation.

The prevalence of ACOS in the general population ranges from 1.6 to $4.5 \%$ in different studies $^{61}$. If only COPD subjects are included, the prevalence of ACOS ranges from 12.1 to $55.2 \%{ }^{61}$. The wide variation in prevalence is related to the diagnostic criteria applied, together with the population being studied.

Figure 3 shows the prevalence of ACOS in PLATINO using different definitions and different denominators for calculating the prevalence. In general, subjects with ACOS had more respiratory symptoms, worse lung function, used more respiratory medication, and had more hospitalizations and exacerbations and worse general health status ${ }^{62}$. After adjusting for confounders, ACOS was associated with higher risk for exacerbations and hospitalizations and worse general health status compared with COPD-only subjects $^{62}$.

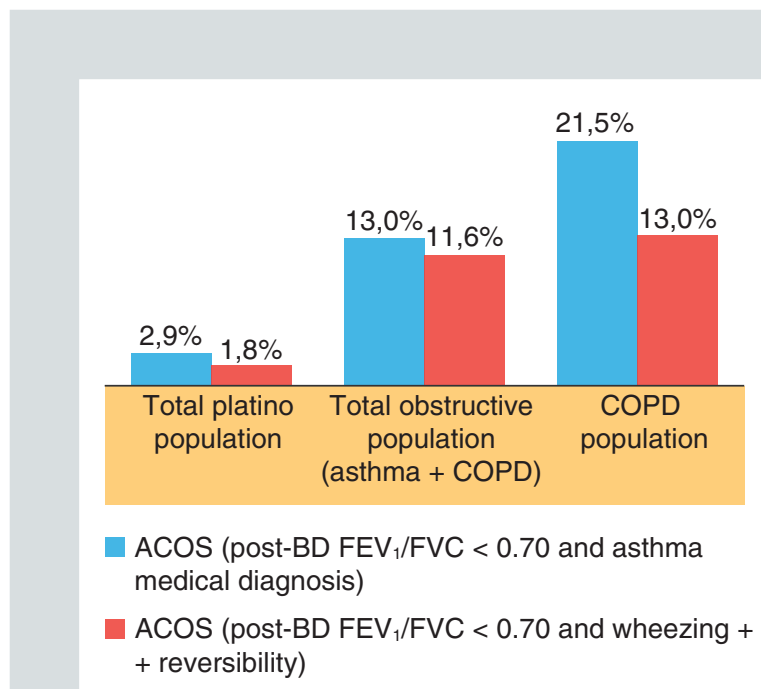

Figure 3. Asthma-COPD overlap syndrome prevalence using different definitions in the total PLATINO population, total obstructive population (asthma + COPD), and COPD population (PLATINO baseline).

$\mathrm{BD}$ : bronchodilator; $\mathrm{FEV}_{1}$ : forced expiratory volume in 1 second; FVC: forced vital capacity ; ACOS: asthma-COPD overlap syndrome.

The results of two recent systematic reviews showed that ACOS patients have higher healthcare utilization, higher exacerbation rates, more symptoms, and lower quality of life $\mathrm{e}^{63,64}$.

In summary, the available information indicates that criteria used to define ACOS and the population used to calculate prevalence has a significant influence on prevalence. Additionally, ACOS represents a clinical phenotype associated with more frequent adverse outcomes than either asthma or COPD, which probably indicates a different management approach.

\section{COPD in non-smokers}

Although smoking is widely recognized as the most important risk factor for COPD, it is now acknowledged that the disease also occurs in non-smokers. 


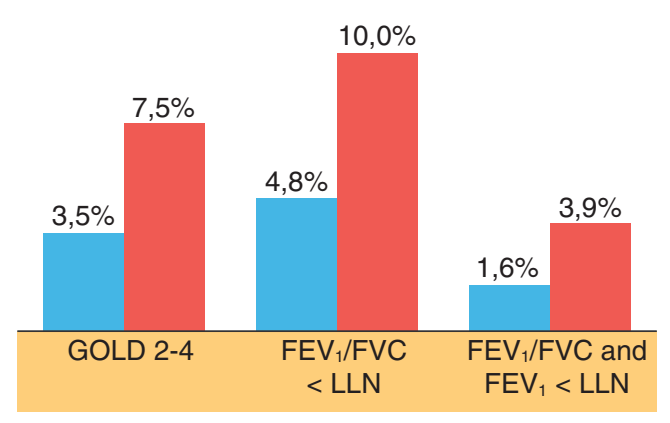

Never-smokers Ever-smokers

Figure 4. Population prevalence of COPD by different spirometric criteria and smoking status (PLATINO baseline).

$\mathrm{FEV}_{1}$ : forced expiratory volume in 1 second; FVC: forced vital capacity; LLN: lower limit of normal.

The BOLD study described the characteristics of COPD in never-smokers and their risk factors $^{65}$. Among never-smokers, $6.6 \%$ met the criteria for mild COPD (GOLD instead 1), and $5.6 \%$ met the criteria for GOLD grades $\geq 2$. Never-smokers made up $27.7 \%$ of all COPD cases: $33.0 \%$ of all GOLD grades 1 cases and $23.3 \%$ of all GOLD grades $\geq 2$ cases. Predictors of COPD in never-smokers include age, education, occupational exposure, childhood respiratory diseases, and BMI alterations ${ }^{65}$.

Among PLATINO populations, $43 \%$ were never-smokers and 57\% ever-smokers. COPD was observed in $3.5 \%$ of never-smokers and in $7.5 \%$ of ever-smokers. Figure 4 shows the COPD prevalence by different spirometric criteria and smoking status. The prevalence of COPD (GOLD grades $\geq 2$ ) in never-smokers was 3.5\%. Never-smoker patients with COPD (GOLD grades 2-4) were more likely to be older, female, with previous diagnosis of asthma and tuberculosis and higher $\mathrm{FEV}_{1}$, response to bronchodilators, reporting more commonly

exacerbations requiring medical consultation or hospitalization, and less passive smoking exposure than ever-smokers with $\mathrm{COPD}^{66}$.

Recently, an analysis of the data from 5,176 adults ( $\geq 40$ years) who participated in the Canadian Cohort of Obstructive Lung Disease (CanCOLD) study showed that the COPD prevalence $\left(\mathrm{FEV}_{1} / \mathrm{FVC}<\mathrm{LLN}\right)$ in never-smokers was $6.4 \%$, constituting $27 \%$ of all COPD subjects $^{67}$. Independent predictors of COPD in never-smokers and ever-smokers were older age, self-reported asthma, and lower education. In never-smokers, a history of hospitalization in childhood for respiratory illness was discriminative, while exposure to passive smoke and biomass fuel for heating was discriminative for women ${ }^{67}$.

The results from these epidemiologic studies confirm the evidence that never-smokers comprise a substantial proportion of individuals with COPD. The main factors associated with an increased risk for COPD for both genders were: increased age, prior diagnosis of asthma, lower education levels, exposure to organic dusts in the workplace, and childhood respiratory diseases. In addition, studies suggest gender-specific risk factors for COPD in never-smoker women (exposure to passive smoke and biomass fuel for heating).

\section{PLATINO FOLLOW-UP STUDY CONTRIBUTION}

\section{Design and general characteristics of the study}

The PLATINO longitudinal study was performed in three of the original five PLATINO 
TABLE 1. Overall response rates of interviews and spirometry of localized subjects in the PLATINO follow-up study

\begin{tabular}{|l|c|c|c|}
\hline & Montevideo (Uruguay) & Santiago de Chile (Chile) & Sao Paulo (Brazil) \\
\hline Response only interviews, (\%) & 0.5 & 3.6 & 1.8 \\
\hline Response of interviews plus spirometry, (\%) & 78.6 & 76.7 & 63.2 \\
\hline Deaths, refusals and losses, (\%) & 21.0 & 20.0 & 35.0 \\
\hline
\end{tabular}

sites, with a high follow-up rate and spirometry quality. It was performed on the same individuals, using the same spirometers and techniques ${ }^{68}$. Selection of the follow-up centres was determined by the level of COPD prevalence in the baseline study. The first site was Montevideo due to the highest COPD prevalence $(19.7 \%)$, Santiago had the second highest prevalence $(16.9 \%)$ and the highest smoking prevalence $(38.6 \%)$, and Sao Paulo was third in prevalence (15.8\%). The time interval between two visits in each of the centres range from 5, 6, to 9 years in Montevideo, Santiago, and Sao Paulo, respectively ${ }^{68}$. In Montevideo $85.6 \%$ of patients were located and interviewed, $84.7 \%$ in Santiago, and $77.7 \%$ in Sao Paulo ${ }^{68}$. The overall response rates of interviews and spirometry of localized subjects in the PLATINO follow-up is shown in table 1 . The general quality of spirometry was $\geq 80 \%$ according to ATS criteria ${ }^{68}$. A total of 71 deaths were documented in Montevideo, 95 in Santiago, and 135 in Sao Paulo, and death certificates were obtained from the national mortality registries for 76.1, 88.3, and $91.8 \%$ of cases, respectively ${ }^{68}$.

\section{COPD prevalence over time and diagnosis stability}

COPD is characterized by persistent airflow limitation; therefore, by definition, variations over time from the presence to the absence of airflow limitation are not compatible with disease diagnosis and in theory would represent COPD misdiagnosis.

Variations in the overall COPD prevalence according to different spirometric criteria were assessed using PLATINO baseline and follow-up data (Fig. 5). Using the diagnostic criteria post-BD $\mathrm{FEV}_{1} / \mathrm{FVC}<0.70$, COPD prevalence among centres varied in the baseline study from $15.7 \%$ in Sao Paulo to $19.5 \%$ in Montevideo, and markedly in the follow-up (from $8.5 \%$ in Sao Paulo to $27.5 \%$ in Montevideo) ${ }^{69}$. Similar changes were observed by using the post-BD $\mathrm{FEV}_{1} / \mathrm{FVC}<\mathrm{LLN}$ criteria (baseline from $8.5 \%$ in Santiago to $9.8 \%$ in Montevideo, and in the follow-up from $6.0 \%$ in Sao Paulo to $13.2 \%$ in Montevideo) ${ }^{69}$. Variations were lower using the GOLD stages 2-4 definition (baseline from 5.8\% in Santiago to $7.8 \%$ in Montevideo, and in the follow-up from $5.3 \%$ in Sao Paulo to $8.4 \%$ in Montevideo) and the $\mathrm{FEV}_{1} / \mathrm{FEV}_{6}<\mathrm{LLN}$ criteria (baseline from $7.5 \%$ in Santiago to $9.7 \%$ in Montevideo and in the follow-up from $7.9 \%$ in Santiago to $10.6 \%$ in Montevideo ${ }^{69}$. These changes were associated with differences in the forced expiratory time (FET) between the two surveys (shortest mean FET in Sao Paulo and longest in Montevideo) ${ }^{69}$. The results suggest that the $\mathrm{FEV}_{1} / \mathrm{FEV}_{6}$ ratio is associated with lower variations than $\mathrm{FEV}_{1} / \mathrm{FCV}$, in part 


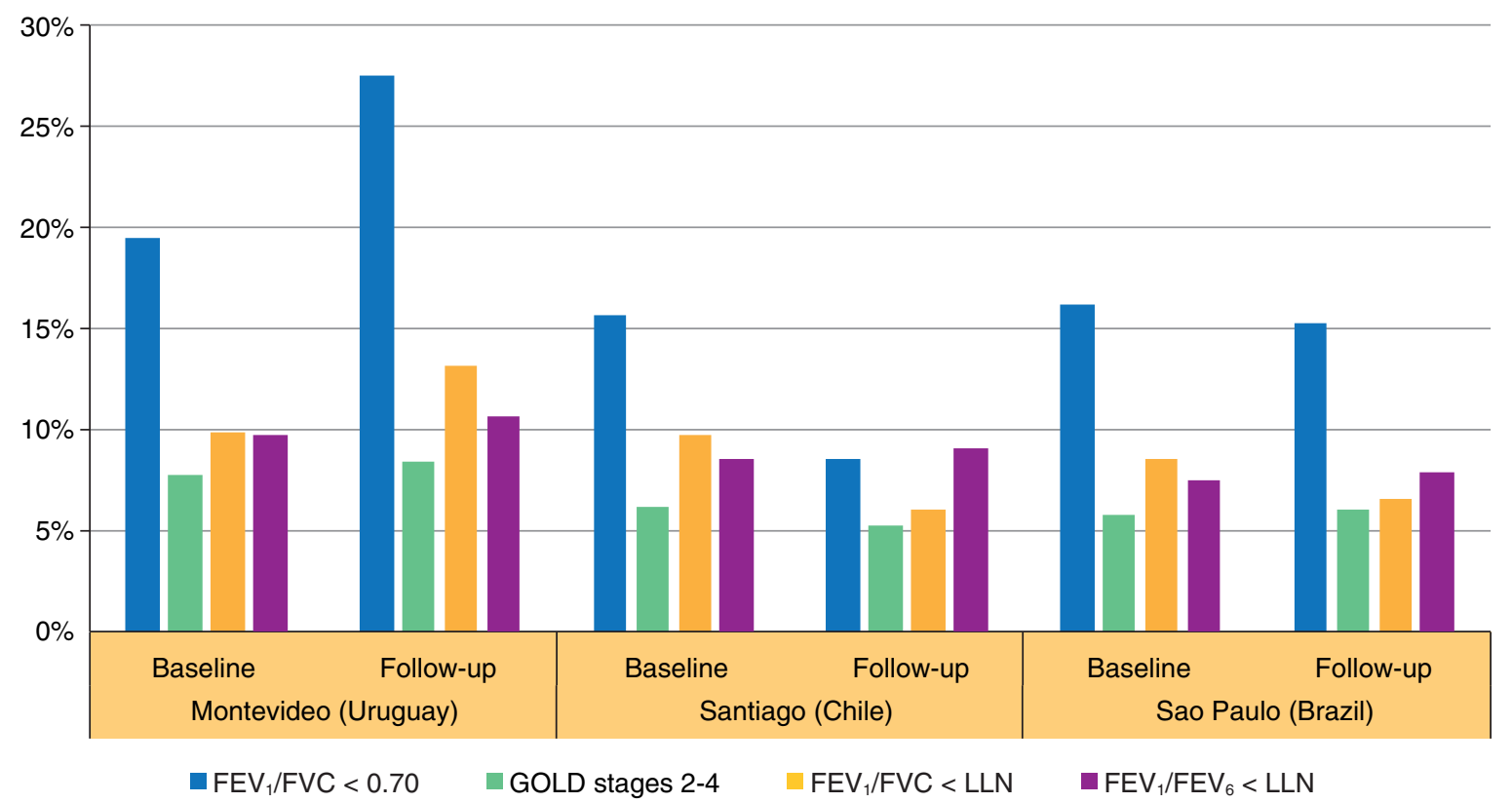

FIGURE 5. Changes in the COPD prevalence (\%) after the use of bronchodilator by different spirometric criteria in the PLATINO follow-up study.

$\mathrm{FEV}_{1}$ : forced expiratory volume in 1 second; FEV $_{6}$ : forced expiratory volume in 6 seconds; FVC: forced vital capacity; LLN: lower limit of normal.

due to FVC varying with the duration of the forced exhalation ${ }^{69}$.

Inconsistency in the COPD diagnosis over time in the PLATINO follow-up study was also assessed and defined as the percentage of participants with a change in diagnosis of airflow limitation (either a new diagnosis in the second evaluation or the presence of airflow obstruction in the first evaluation but not in the second). Inconsistent diagnoses occurred with all COPD spirometric criteria, but were more common when using the post-BD FEV $1 / \mathrm{FVC}<0.70$ criterion $(11.7 \%)^{70}$. Post-BD $\mathrm{FEV}_{1} / \mathrm{FVC}<\mathrm{LLN}$ criterion showed an intermediate inconsistency (6.5\%), $\mathrm{FEV}_{1}$ / $\mathrm{FEV}_{6}<\mathrm{LLN}$ criterion $5.9 \%$, and the lowest value was for GOLD grades 2-4 $(4.1 \%)^{70}$. Using $\mathrm{FEV}_{1} / \mathrm{FEV}_{6}<\mathrm{LLN}$ or GOLD stage $2-4$ as the criterion for airflow obstruction reduces inconsistencies in the COPD diagnosis over time ${ }^{70}$.

These analyses provide important information on the variations and changes of the COPD diagnosis over time and the factors associated with these changes.

\section{General mortality in the PLATINO study population}

COPD and poor lung function are important predictors for all-cause cardiovascular and respiratory mortality ${ }^{71-73}$. 
Mortality rates according to COPD status and lung function measured at baseline were analysed in PLATINO. Deaths were more common among men, and survival curves were similar in all sites ${ }^{74}$. Cardiovascular and respiratory disease and cancer were the main causes of death. Cardiovascular disease was the leading cause of death for both sexes in Santiago and Sao Paulo, and for men in Montevideo, followed by cancer and respiratory deaths ${ }^{74}$.

Spirometric criteria for COPD at baseline was associated with all-cause mortality (HR: 1.43 for $\mathrm{FEV}_{1} / \mathrm{FVC}<\mathrm{LLN}$; 2.01 for GOLD 2-4; 1.46 for GOLD 1-4; 1.50 for $\left.\mathrm{FEV}_{1} / \mathrm{FEV}_{6}<\mathrm{LLN}\right)^{74}$. For cardiovascular mortality, significant associations were found: GOLD grades 2-4 (HR: 2.68) and GOLD 1-4 (HR: 1.78) ${ }^{74}$. Including lung cancer among respiratory causes of mortality, the results were quite similar.

The $\mathrm{FEV}_{1}$ was a better predictor of mortality than $\mathrm{FVC}^{74}$. Low $\mathrm{FEV}_{1}$ was a predictor for all causes and respiratory mortality in both genders and for cardiovascular mortality in men, whereas FVC was not associated with overall mortality ${ }^{74}$. COPD and low $\mathrm{FEV}_{1}$ are important predictors for overall and cardiovascular mortality in Latin America ${ }^{74}$.

These findings are consistent with the literature, although it is controversial as to which parameter shows the greatest predictive ability from evidence coming from cohort studies ${ }^{71-73}$.

\section{CONCLUSION}

The PLATINO baseline and follow-up studies, beyond providing data on COPD epidemiology, offer an opportunity to characterize disease clinical features, management, stability of diagnosis, and mortality associated factors in Latin America.

\section{CONFLICT OF INTEREST}

Dr. Montes de Oca has nothing to disclose, Dr. Lopez Varela reports personal fees from Boehringer Ingelheim, personal fees from Novartis, personal fees from AstraZeneca, outside the submitted work.

\section{REFERENCES}

1. Caballero A, Torres-Duque CA, Jaramillo C, et al. Prevalence of COPD in Five Colombian Cities Situated at Low, Medium, and High Altitude (PREPOCOL Study). Chest. 2008;133:343-9.

2. Menezes AM, Victora CG, Perez-Padilla R, Team P. The Platino project: methodology of a multicenter prevalence survey of chronic obstructive pulmonary disease in major Latin American cities. BMC Med Res Methodol. 2004;4:15.

3. Menezes AM, Perez-Padilla R, Jardim JR, et al. Chronic obstructive pulmonary disease in five Latin American cities (the PLATINO study): a prevalence study. Lancet. 2005;366:1875-81

4. Lozano R, Naghavi M, Foreman K, et al. Global and regional mortality from 235 causes of death for 20 age groups in 1990 and 2010: a systematic analysis for the Global Burden of Disease Study 2010. Lancet. 2012; 380:2095-128.

5. Vos T, Flaxman AD, Naghavi M, et al. Years lived with disability (YLDs) for 1160 sequelae of 289 diseases and injuries 1990-2010: a systematic analysis for the Global Burden of Disease Study 2010. Lancet. 2012;380 2163-96.

6. Zhong N, Wang C, Yao W, et al. Prevalence of chronic obstructive pulmonary disease in China. Am J Respir Crit Care Med. 2007;176:753-60.

7. Perez-Padilla R, Hallal PC, Vazquez-Garcia JC, et al. Impact of bronchodilator use on the prevalence of COPD in population-based samples. COPD. 2007;4:113-20.

8. Buist AS, McBurnie MA, Vollmer WM, et al. International variation in the prevalence of COPD (The BOLD Study): a population-based prevalence study. Lancet. 2007;370:741-50.

9. Hooper R, Burney P, Vollmer WM, et al. Risk factors for COPD spirometrically defined from the lower limit of normal in the BOLD project. Eur Respir J. 2012;39:1343-53.

10. Talamo C, de Oca MM, Halbert R, et al. Diagnostic labeling of COPD in five Latin American cities. Chest. 2007;131:60-7.

11. Lamprecht B, Soriano JB, Studnicka M, et al. Determinants of underdiagnosis of COPD in national and international surveys. Chest. 2015; 148:971-85.

12. Price D, West D, Brusselle G, et al. Management of COPD in the UK primary-care setting: an analysis of real-life prescribing patterns. Int J Chron Obstruct Pulmon Dis. 2014;9:889-905. 
13. Montes de Oca M, Lopez Varela MV, Jardim J, Stirvulov R, Surmont F. Bronchodilator treatment for COPD in primary care of four Latin America countries: The multinational, cross-sectional, non-interventional PUMA study. Pulm Pharmacol Ther. 2016;38:10-6.

14. Lopez Varela MV, Muino A, Perez Padilla R, et al. [Treatment of chronic obstructive pulmonary disease in 5 Latin American cities: the PLATINO study]. Arch Bronconeumol. 2008;44:58-64.

15. Montes de Oca M, Talamo C, Perez-Padilla R, et al. Use of respiratory medication in five Latin American cities: The PLATINO study. Pulm Pharmacol Ther. 2008;21:788-93.

16. Perez-Padilla R, Valdivia G, Muino A, et al. [Spirometric reference values in 5 large Latin American cities for subjects aged 40 years or over]. Arch Bronconeumol. 2006;42:317-25.

17. Perez-Padilla R, Torre Bouscoulet L, Vazquez-Garcia JC, et al. [Spirometry reference values after inhalation of 200 microg of salbutamol]. Arch Bronconeumol. 2007;43:530-4.

18. Calverley PM, Burge PS, Spencer S, Anderson JA, Jones PW. Bronchodilator reversibility testing in chronic obstructive pulmonary disease. Thorax. 2003;58:659-64

19. Tashkin DP, Celli B, Senn S, et al. A 4-year trial of tiotropium in chronic obstructive pulmonary disease. N Engl J Med. 2008;359:1543-54.

20. Anthonisen NR, Lindgren PG, Tashkin DP, Kanner RE, Scanlon PD, Connett JE. Bronchodilator response in the lung health study over 11 yrs. Eur Respir J. 2005; 26:45-51.

21. Montes de Oca M, Perez-Padilla R, Talamo C, et al. Acute bronchodilator responsiveness in subjects with and without airflow obstruction in five Latin American cities: the PLATINO study. Pulm Pharmacol Ther. 2010;23: 29-35.

22. Tan WC, Vollmer WM, Lamprecht B, et al. Worldwide patterns of bronchodilator responsiveness: results from the Burden of Obstructive Lung Disease study. Thorax. 2012;67:718-26.

23. Perez-Padilla R, Vollmer WM, Vazquez-Garcia JC, et al. Can a normal peak expiratory flow exclude severe chronic obstructive pulmonary disease? Int J Tuberc Lung Dis. 2009;13:387-93.

24. Jithoo A, Enright PL, Burney P, et al. Case-finding options for COPD: results from the Burden of Obstructive Lung Disease Study. Eur Respir J. 2013;41: 548-55.

25. McGarvey LP, John M, Anderson JA, Zvarich M, Wise RA. Ascertainment of cause-specific mortality in COPD: operations of the TORCH Clinical Endpoint Committee. Thorax. 2007;62:411-5.

26. Divo M, Cote C, Torres JP, et al. Comorbidities and risk of mortality in patients with chronic obstructive pulmonary disease. Am J Respir Crit Care Med. 2012;186:155-61.

27. Burgel PR, Escamilla R, Perez T, et al. Impact of comorbidities on COPD-specific health-related quality of life. Respir Med. 2013;107:233-41.

28. Cazzola M, Bettoncelli G, Sessa E, Cricelli C, Biscione G. Prevalence of comorbidities in patients with chronic obstructive pulmonary disease. Respiration. 2010;80:112-9.

29. Crisafulli E, Costi S, Luppi F, et al. Role of comorbidities in a cohort of patients with COPD undergoing pulmonary rehabilitation. Thorax. 2008;63: 487-92.

30. Chatila WM, Thomashow BM, Minai OA, Criner GJ, Make BJ. Comorbidities in chronic obstructive pulmonary disease. Proc Am Thorac Soc. 2008; 5:549-55.

31. Lopez Varela MV, Montes de Oca M, Halbert R, et al. Comorbidities and health status in individuals with and without COPD in five Latin American cities: the PLATINO study. Arch Bronconeumol. 2013;49:468-74.

32. World Health Organization (WHO). Chronic obstructive pulmonary disease (COPD). Updated 2015. Available at: http:/ / www.who.int/respiratory/copd/en/ (Accessed 20 July 2015).

33. Laurin C, Lavoie KL, Bacon SL, et al. Sex differences in the prevalence of psychiatric disorders and psychological distress in patients with COPD. Chest. 2007:132:148-55
34. Chavannes N, Huibers M, Schermer T, et al. Associations of depressive symptoms with gender, body mass index and dyspnea in primary care COPD patients. Fam Pract. 2005;22:604-7.

35. Martinez FJ, Curtis JL, Sciurba F, et al. Sex differences in severe pulmonary emphysema. Am J Respir Crit Care Med. 2007;176:243-52.

36. de Torres JP, Casanova C, Hernández C, Abreu J, Aguirre-Jaime A, Celli BR. Gender and COPD in patients attending a pulmonary clinic. Chest. 2005 128:2012-6.

37. de Torres JP, Casanova C, Hernández C, et al. Gender associated difference in determinants of quality of life in patients with COPD: a case series study. Health Qual Life Outcomes. 2006;4:72.

38. Oga T, Nishimura K, Tsukino M, Sato S, Hajiro T. Analysis of the factor related to mortality in chronic obstructive pulmonary disease. Am J Respir Crit Care Med. 2003;167:544-9.

39. de Torres JP, Cote CG, López MV, et al. Sex differences in mortality in patients with COPD. Eur Respir J. 2009;33:528-35.

40. Lopez Varela MV, Montes de Oca M, Halbert RJ, et al. Sex-related differ ences in COPD in five Latin American cities: the PLATINO study. Eur Respir J. 2010;36:1034-41.

41. Landbo C, Prescott E, Lange P, Vestbo J, Almdal TP. Prognostic value of nutritional status in chronic obstructive pulmonary disease. Am J Respir Crit Care Med. 1999;160:1856-61.

42. Vestbo J, Prescott E, Almdal T, et al. Body mass, fat-free body mass, and prognosis in patients with chronic obstructive pulmonary disease from a random population sample. Am J Respir Crit Care Med. 2006 173:79-83.

43. Montes de Oca M, Talamo C, Perez-Padilla R, et al. Chronic obstructive pulmonary disease and body mass index in five Latin America cities: the PLATINO study. Respir Med. 2008;102:642-50.

44. Vanfleteren LE, Lamprecht B, Studnicka M, et al. Body mass index and chronic airflow limitation in a worldwide population-based study. Chron Respir Dis. 2016;13:90-101.

45. Celli BR, Thomas NE, Anderson JA, et al. Effect of pharmacotherapy on rate of decline of lung function in chronic obstructive pulmonary disease. Am J Respir Crit Care Med. 2008;178:332-8.

46. Seemungal TA, Donaldson GC, Paul EA, Bestall JC, Jeffries DJ, Wedzicha JA. Effect of exacerbation on quality of life in patients with chronic obstructive pulmonary disease. Am J Respir Crit Care Med. 1998;157 1418-22.

47. Jones PW, Lamarca R, Chuecos F, et al. Characterisation and impact of reported and unreported exacerbations: results from ATTAIN. Eur Respir J. 2014;44:1156-65.

48. Spencer S, Jones PW. Time course of recovery of health status following an infective exacerbation of chronic bronchitis. Thorax. 2003;58:589-93.

49. Suissa S, Dell'Aniello S, Ernst P. Long-term natural history of chronic obstructive pulmonary disease: severe exacerbations and mortality. Thorax. 2012;67:957-63.

50. Punekar YS, Shukla A, Müllerova H. COPD management costs according to the frequency of COPD exacerbations in UK primary care. Int J Chron Obstruct Pulmon Dis. 2014;9:65-73.

51. Nielsen R, Johannessen A, Benediktsdottir B, et al. Present and future costs of COPD in Iceland and Norway: results from the BOLD study. Eur Respir J. 2009;34:850-7.

52. Örnek T, Tor M, Altın R, et al. Clinical factors affecting the direct cost of patients hospitalized with acute exacerbation of chronic obstructive pulmonary disease. Int J Med Sci. 2012;9:285-90.

53. Pasquale MK, Sun SX, Song F, Hartnett HJ, Stemkowski SA. Impact of exacerbations on health care cost and resource utilization in chronic obstructive pulmonary disease patients with chronic bronchitis from a predominantly Medicare population. Int J Chron Obstruct Pulmon Dis. 2012;7:757-64.

54. Hurst JR, Vestbo J, Anzueto A, et al. Susceptibility to exacerbation in chronic obstructive pulmonary disease. N Engl J Med. 2010;363:1128-38. 
55. de Oca MM, Talamo C, Halbert RJ, et al. Frequency of self-reported COPD exacerbation and airflow obstruction in five Latin American cities: the Proyecto Latinoamericano de Investigacion en Obstruccion Pulmonar (PLATINO) study. Chest. 2009;136:71-8.

56. Corhay JL, Vincken W, Schlesser M, Bossuyt P, Imschoot J. Chronic bronchitis in COPD patients is associated with increased risk of exacerbations: a cross-sectional multicentre study. Int J Clin Pract. 2013; 67:1294-301.

57. Kim V, Criner GJ. Chronic bronchitis and chronic obstructive pulmonary disease. Am J Respir Crit Care Med. 2013;187:228-37.

58. Choi JY, Yoon HK, Park SJ, et al. Chronic bronchitis is an independently associated factor for more symptom and high-risk groups. Int $\mathrm{J}$ Chron Obstruct Pulmon Dis. 2016;11:1335-41.

59. Kim V, Han MK, Vance GB, et al. The chronic bronchitic phenotype of COPD: An analysis of the COPDGene Study. Chest. 2011;140:626-33.

60. de Oca MM, Halbert RJ, Lopez MV, et al. The chronic bronchitis phenotype in subjects with and without COPD: the PLATINO study. Eur Respir J. 2012;40:28-36

61. Wurst KE, Kelly-Reif K, Bushnell GA, Pascoe S, Barnes N. Understanding asthma-chronic obstructive pulmonary disease overlap syndrome. Respir Med. 2016;110:1-11.

62. Menezes AM, Montes de Oca M, Perez-Padilla R, et al. Increased risk of exacerbation and hospitalization in subjects with an overlap phenotype: COPD-asthma. Chest. 2014;145:297-304.

63. Nielsen M, Bårnes CB, Ulrik CS. Clinical characteristics of the asthmaCOPD overlap syndrome - a systematic review. Int J Chron Obstruct Pulmon Dis. 2015;10:1443-54.

64. Alshabanat A, Zafari Z, Albanyan O, Dairi M, FitzGerald JM. Asthma and COPD Overlap Syndrome (ACOS): A systematic review and meta analysis. PLoS One. 2015;10:e0136065.
65. Lamprecht B, McBurnie MA, Vollmer WM, et al. COPD in never smokers: Results from the population-based Burden of Obstructive Lung Disease Study. Chest. 2011;139:752-63.

66. Perez-Padilla R, Fernandez R, Lopez Varela MV, et al. Airflow obstruction in never smokers in five Latin American cities: the PLATINO study. Arch Med Res. 2012;43:159-65.

67. Tan WC, Sin DD, Bourbeau J, et al. Characteristics of COPD in never-smokers and ever-smokers in the general population: results from the CanCOLD study. Thorax. 2015;70:822-9.

68. Menezes AM, Muino A, Lopez-Varela MV, et al. A population-based cohort study on chronic obstructive pulmonary disease in Latin America: methods and preliminary results. The PLATINO Study Phase II. Arch Bronconeumol 2014;50:10-7.

69. Perez-Padilla R, Wehrmeister FC, Celli BR, et al. Reliability of FEV1/FEV6 to diagnose airflow obstruction compared with FEV1/FVC: the PLATINO longitudinal study. PLoS One. 2013;8:e67960.

70. Perez-Padilla R, Wehrmeister FC, Montes de Oca M, et al. Instability in the COPD diagnosis upon repeat testing vary with the definition of COPD. PLoS One. 2015;10:e121832.

71. Baughman P, Marott JL, Lange P, et al. Combined effect of lung function level and decline increases morbidity and mortality risks. Eur J Epidemiol. 2012;27:933-43.

72. Mannino D, Buist A, Petty T, Enright P, Redd S. Lung function and mortality in the United States: data from the First National Health and Nutrition Examination Survey follow up study. Thorax. 2003;58:388-93.

73. Schunemann HJ, Dorn J, Grant BJ, Winkelstein W, Trevisan M. Pulmonary function is a long-term predictor of mortality in the general population: 29-year follow-up of the Buffalo Health Study. Chest. 2000;118:656-64.

74. Menezes AM, Perez-Padilla R, Wehrmeister FC, et al. FEV1 is a better predic tor of mortality than FVC: the PLATINO cohort study. PLoSOne. 2014;9:e109732. 